\title{
Perception of Rural Communities in Akoko North West Local Government Area of Ondo State Nigeria towards Ikaram Millennium Village Project
}

\author{
Article by Kareem Adesola Olawumi \\ Public Health, Texila American University \\ E-mail:drsolad@gmail.com
}

\begin{abstract}
Background: Millennium Village Project (MVP) is designed to harness the progress of the timebound Millennium Development Goals (MDGs).

Objective: This study aimed to assess the perception of the Ikaram Millennium Village Project by the residents of Akoko North-West Local Government Area of Ondo State.

Method: A descriptive cross-sectional study of 496 residents of five out of the seven communities that make up the Ikaram MVP was done. The perceptions of the respondents were rated poor or good by scoring response to eight validated questions. Chi square test was used to assess significant association.

Result: The mean age of the respondents was 42.20 17.1 years, 250 (50.4\%) were females, married were 311 (62.7\%). Only 15(3\%) were from other tribes aside Yoruba, 430(86.7\%) have ever accessed the MVP health services. Poor perception was reported among 353 (82.1\%) respondents. Among the Yorubas 79(17.1\%) had good perception compared to 7(46.7\%) from other tribes, $p=$ 0.003. The location of the health facility contributed to the poor perception about the Ikaram MVP.

Conclusion: For community orientated health projects to be successful community participation is important.
\end{abstract}

Keywords: Millennium Village project, rural communities, perception, health facilities, community participation.

\section{Introduction}

The Millennium Development goals (MDGs) were introduced at the millennium summit in 2000 with the aim of addressing the problems impeding growth especially in developing countries by $2015^{1}$. The millennium village project (MVP) was established in the year 2005 reaching nearly 500,000 people in rural villages across 10 countries in sub-Saharan Africa, through collaboration between UNDP, Millennium Promise, The Earth Institute at Colombia University and the Japanese Government to relieve poverty and improve health in developing countries thereby aiding the timed accomplishment of the MDG's goal ${ }^{1,2,3}$

The specific principles which MVP is designed is to harness three interconnected principles and components which include the principles of community participation and leadership; science-based innovations and local knowledge; a costed national action plan for reaching the time-bounded and targeted objectives of the MDGs ${ }^{4}$.

In Nigeria (sub-Sahara Africa), the MVP was located in two sites which are Pampaida (Kaduna state) and Ikaram (Ondo state) ${ }^{1}$. The Ikaram MVP project had two sites: research village MV1 and the cluster of villages under MV2. These two sites included a cluster of 7 villages located in Akoko North-west local government area of Ondo State in the South-Western part of Nigeria. The first phase of the project was established in May 16, 2006 while the second phase began in the year 2011, overall project management was from United Nations Development Programme (UNDP) with support from Ondo State government. The Federal Medical Centre, Owo became formally involved in the project during the second phase ${ }^{6,7}$.

Several interventions were pursued simultaneously in the Millennium Village Project encompassing agriculture, health, education, infrastructure (including water and sanitation), and business development. The intervention package which is given priority is community specific ${ }^{1}$. 
Although the Ikaram MVP has been on-going for the over 8 years there has been no assessment of the perception of the rural communities in the Akoko North-West Local Government Area. With community participation being a key principle for the MVP project, assessing community perception will be important to improving project outcomes. This study aimed to assess the perception of the Ikaram Millennium Village Project by the residents of Akoko North-West Local Government Area of Ondo State.

\section{Methods}

2.1 Study Design and Study Area

The study area is comprised of rural communities that are beneficiaries of the Ikaram Millennium Village Project (MVP) services, especially the clinical services. The Ikaram MVP services include ICT training and services, Poultry and agriculture, clinical services such as out-patient, pregnancy care, and surgical services.

\section{Study population, inclusion and exclusion criteria}

Residents of the communities who were age 18years and above, with at least one year residence in Akoko North-West LGA were interviewed. A cross sectional study design was employed. Multistage sampling technique was used. Stage 1: Five communities were selected using simple random sampling out of the seven communities in the Ikaram MVP. Stage 2: A ward was selected from each community using simple random sampling. Stage 3: From all the households in each of the five selected wards, one adult per household was selected as respondent. In a household with more than one qualified respondent one was selected by balloting. Almost $50 \%$ of the communities reside in Ikaram village.

\section{Sample size determination}

The required sample size was calculated by using the Leslie Kish formula ${ }^{14}$. Prevalence of $50 \%$ was used in the absence of any previous study. The minimum sample size calculated was 423 . However, 496 respondents were studied in all the selected wards.

\subsection{Sample Collection Instrument}

Data was collected using semi structured interviewer administered questionnaire. Questionnaires were checked for omissions and errors after collection and correction were made where necessary.

\section{Analysis}

Data was analysed with SPSS version 21.0. The Associations between sociodemographic variables respondents' perception were explored using the Chi square test. The perception of the respondents were determined using 8 validated questions with a 5 point Likert scale 'strongly agree', 'agree', 'undecided', 'disagree', 'strongly disagree'. Responses were scored from $1-5$ with 5 being positive response and 1 being negative perception. The total score ranged from 16 to 40, score of 16-32 was taken as a poor perception and 32-40 was rated good perception. A p-value of $<0.05$ was considered to be statistically significant.

\section{Ethical consideration}

Informed consent (written and verbal) was obtained from the respondents, participation was voluntary and there were no consequences for non-participation. Ethical clearance was obtained from Federal Medical Centre Ethical, Research Review Committee, Owo.

\section{Results}

\section{Demographics}

The median age of respondents was 40 years and the range was $18-95$ years while $250(50.4 \%)$ out of the 496 respondents were females. The numbers of married respondents were 311(62.7\%), more than half of the respondents had some formal education and the predominant tribe was Yoruba. Trading was the major source of living (occupation) of the respondents 119 (24\%), following closely was farming $118(23.8 \%)$. 
Out of the 5 villages studied, Ikaram had the highest number of respondents $255(51.4 \%)$. The socio-demographic characteristic of the respondents are summarised in Table 1.

\section{Awareness of ikaram MVP}

Majority of the respondents were aware and have utilized services rendered in Ikaram MVP, especially the outpatient service 422(85.1\%) as shown in Table 2.

\section{Participation of community}

The frequency of participation of the community in the MVP as seen in Table 3 shows that the number of those who were not involved at 340(79.1\%).

\section{Perception of ikaram MVP}

Factors associated with the perception of the Ikaram MVP are as shown in Table 4. Among those who live in Ikaram 74(29.8\%) had good perception compared to only 4(2.9\%) respondents living in Erusu $(\mathrm{P}<0.001)$. Among the Yorubas $79(17.1 \%)$ had good perception compared to $7(46.7 \%)$ from other tribes, $\mathrm{p}=0.003$.

\section{Discussion}

This study on perception of Ikaram Millennium Village Project (MVP) among rural communities in the Akoko North West LGAs was done to evaluate the perception of the residents in the communities. The level of awareness of respondents were high though level of utilization of services rendered in Ikaram MVP was low as well as the level of community participation in the programme. The cause was the primary location of the Ikaram MVP in Ikaram community. The access barrier due to cost of transportation and the belief that "it doesn't belong to us" could affect other communities ${ }^{13}$, though not considered in this study The latter finding could impede the aim of the Millennium Village Project which is targeted towards self-sustainment development (Kanter et al, 2009) ${ }^{2}$.

It is of note that the respondent's community significantly affected their perception of Ikaram MVP. This is associated with the level of awareness of the community and the belief system of the respondents. In a study carried out in Maiduguri, community awareness of the community-based medical education has been shown to be beneficial to the community ${ }^{8}$.

Other tribes' aside Yoruba had better perception of the Ikaram MVP and this might contribute to their involvement. It has been reported that culture also negatively affected the outcome of the project in another study done in Senegal ${ }^{3}$.

The perception of Ikaram MVP and the occupation of the respondents were not significantly related in this study. The absence of professionals and respondents doing white collar jobs could be responsible. This could also be seen in a study done in Potou, it was observed that despite the increase food production resulting from increase in agricultural practises which was their major profession, the level of malnutrition among the children was high ${ }^{3}$. The question to be answered is that could it be as a result of the primary location of the Ikaram MVP which is in Ikaram, though this study did not consider the option.

The valuation of the Ikaram MVP which is the measurement of the impact of the programme on the community residents' well-being which was not part of this study because of the lack of access to the baseline records of the Ikaram MVP. The study done in Potou, also had difficulty in using baseline data, though they were available baseline records but cannot be trusted ${ }^{3,10,11,12}$.

\section{Conclusion}

For community oriented health projects to be successful community participation is important. The poor perception of the communities about the Ikaram MVP and its location contributed to the low level of utilization. This is also a cause of the slow progress towards achieving Millennium Development Goals.

\section{Recommendation}

There is poor literature review on Perception of Millennium Village Project in the participated communities due to non-existing review of the project. There is need for regular review of the Project 
DOI: $10.21522 /$ TIJPH.2013.05.04.Art025

ISSN: $2520-3134$

to enable the organizer and involved parties know where to put extra effort to ensure community participation.

\section{Diagram and tables}

Table 1. Sociodemographic data of respondents

\begin{tabular}{lll}
\hline Variables & Frequency & Percentage \\
\hline Age & & \\
$<20$ & 59 & 10.9 \\
$20-39$ & 185 & 37.3 \\
$40-56$ & 164 & 33.1 \\
$>60$ & 93 & 18.8 \\
Sex & & \\
Male & 246 & 49.6 \\
Female & 250 & 50.4
\end{tabular}

Educational Status

No formal

60

12.1

Primary

161

32.5

Secondary

165

33.3

Tertiary

110

22.2

Marital Status

Single

97

19.6

Married

311

62.7

Separated

23

4.6

Divorced

10

2.0

Widow/Widower

55

11.1

Tribe

Yoruba

481

97.0

Others

15

3.0

Occupation

Civil servant $\quad 77 \quad 15.5$

$\begin{array}{lll}\text { Farming } & 118 & 23.8\end{array}$

Artisan

89

17.9

Student

93

18.8

Trading

119

24.0

Name of Community

Erusu

140

28.2

Gedegede

49

9.9

Ibaram

27

5.4

Ikaram

255

51.4

Iyani

25

5.0

Number of Years Lived in the Community 
$<10$ years

Table 2. Utilization of services available in ikaram MVP* health centre

\begin{tabular}{ll}
\hline Services & Utilising of Services \\
\hline Out-patient & $365(73.6 \%)$ \\
Pregnancy care & $17(3.4 \%)$ \\
Immunization & $71(14.3 \%)$ \\
Surgical & $17(3.4 \%)$
\end{tabular}

*MVP - Millennium village project

Table 3. Community involvement in activities of ikaram-ibaram millennium village project

\begin{tabular}{lcc}
\hline Variable & Frequency & Percentage \\
\hline Involvement in Ikaram MVP $*(\mathbf{n}=\mathbf{4 3 0})$ & & \\
Yes & 90 & 20.9 \\
No & 340 & 79.1 \\
Awareness of members involvement in & & \\
Ikaram MVP $*(\mathbf{n}=\mathbf{4 7 6})$ & 256 & 53.8 \\
Yes & 220 & 46.2 \\
No &
\end{tabular}

*n varies due to non-response to some questions

Table 4. Questions and response on perception of ikaram ibaram mvp

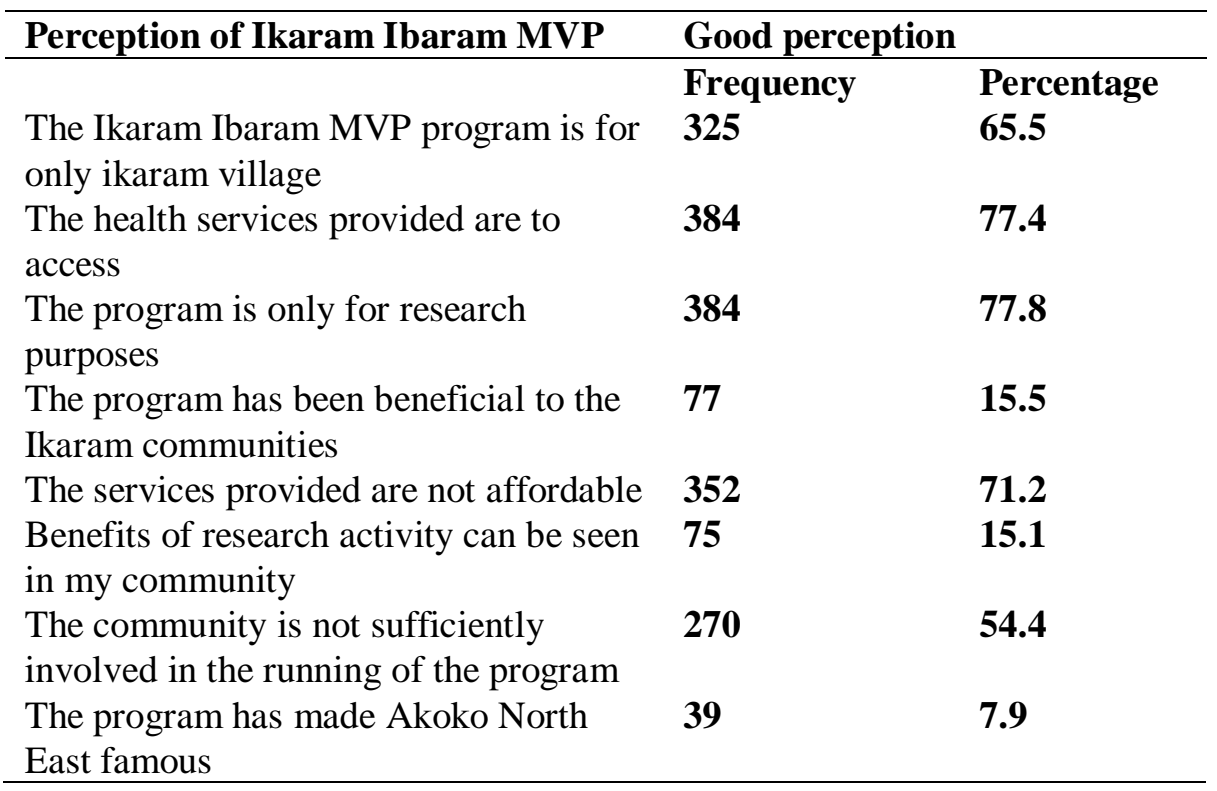


DOI: $10.21522 /$ TIJPH.2013.05.04.Art025

ISSN: $2520-3134$

Table 5. Factors associated with perception of ikaram *MVP

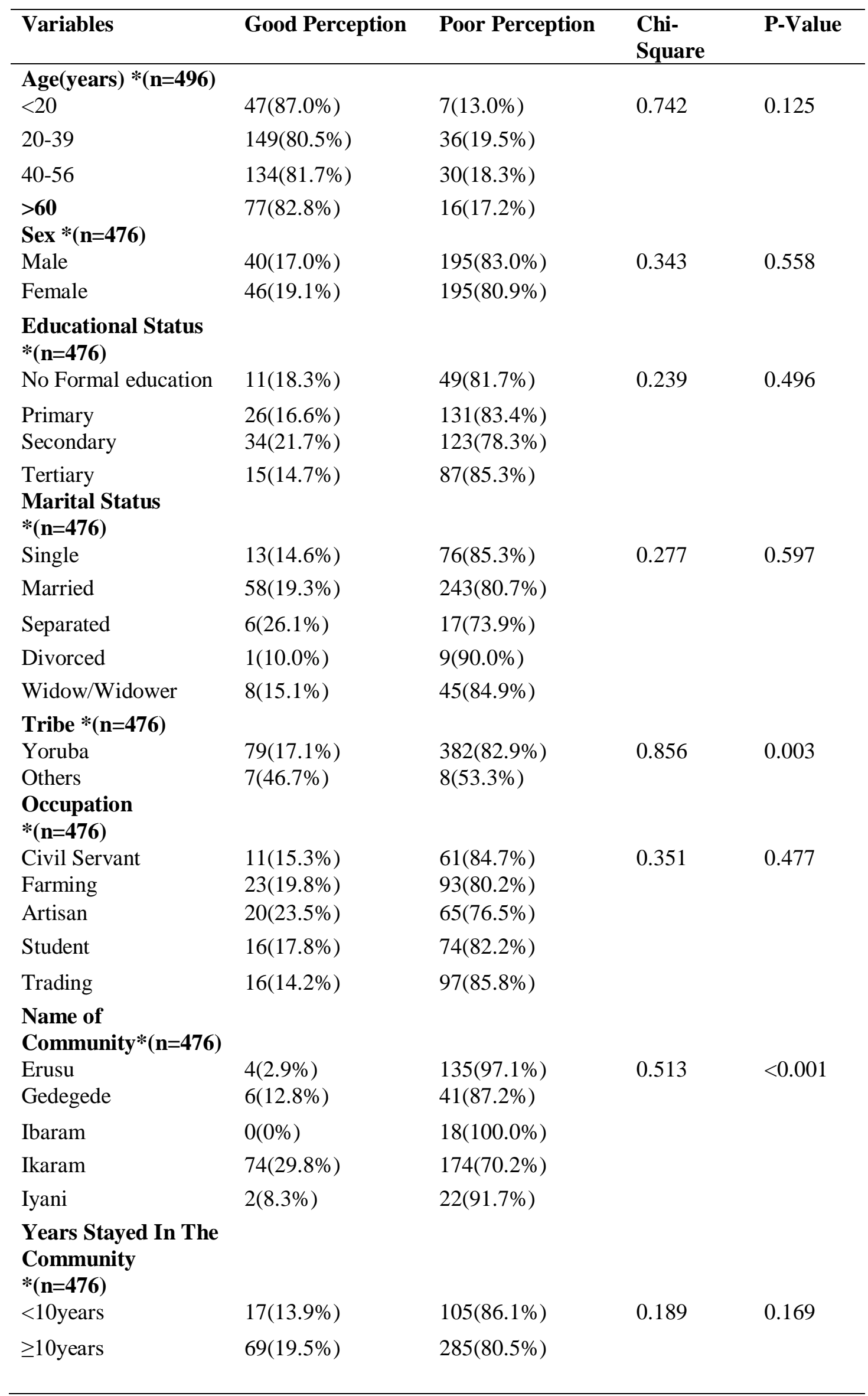


*n varies due to non-response to some questions

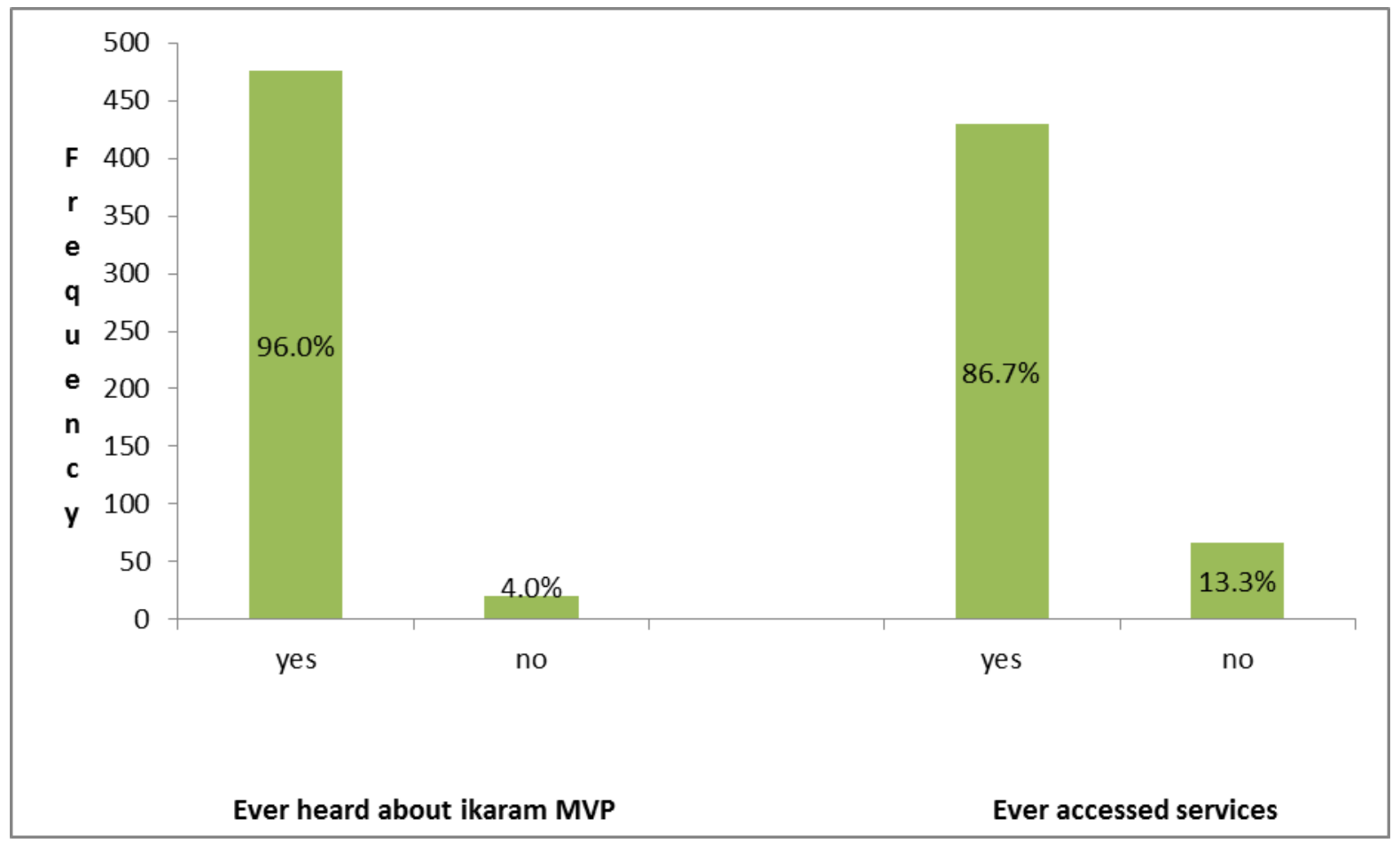

Figure 1. The respondents who have heard about the ikaram MVP and those who have accessed the Services

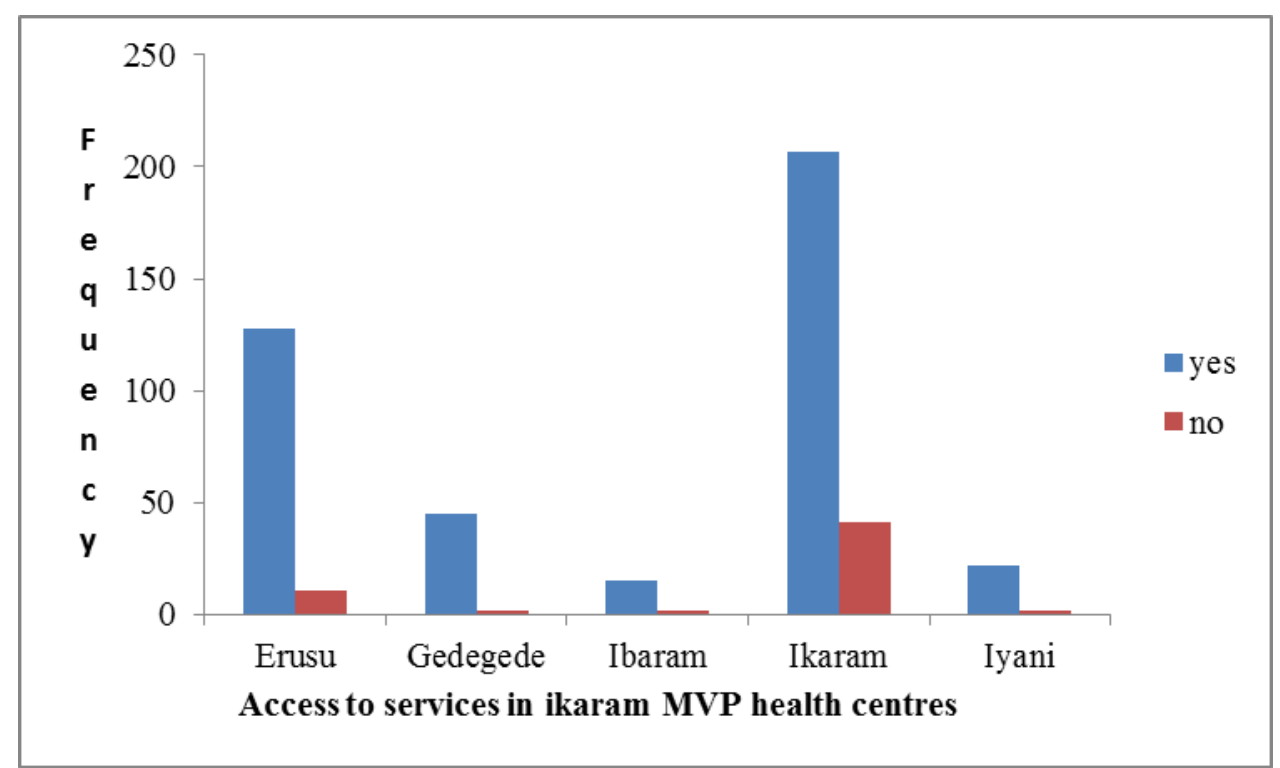

Figure 2. The community members accessing health care services at ikaram millennium village project

\section{References}

[1]. Andrew S. Kanter, Joel Negin, Bernard Olayo et al. Millennium Global Village-Net: Bringing together Millennium Villages throughout sub-Saharan Africa. International journal of medical informatics, 78, 802-807.

[2]. Gertler, P., J., Sebastian M., Patrick P., Laura B., R., Christel M., J., V., (2011). Impact Evaluation in Practice. The World Bank.

[3]. Kish, Leslie (1965): survey sampling. New York: John Wiley and Sons, INc. p. 78-94

[4]. Millennium Villages. www.millenniumvillages.org.

[5]. Millennium Villages Project, (2009b). Study Protocol, Integrating the delivery of health and development interventions: Assessing the impact on child survival in sub-Saharan Africa. https://ciesin.columbia.edu/.../MVPMashego TA, Peltzer K. Curationis. Community perception of quality of 
DOI: $10.21522 / \mathrm{TIJPH} .2013 .05 .04 . \mathrm{Art} 025$

ISSN: $2520-3134$

(primary) health care services in a rural area of Limpopo Province, South Africa: a qualitative study. 2005; 28(2):13-21.Omotara BA, Yahya SJ, Shehu U, Bello HS, Bassi AP. Communities' awareness, perception and participation in the Community-Based Medical Education of the University of Maiduguri. Educ Health (Abingdon). 2006; 19(2):147-54.

[6]. Ousséni Kinda. The Monitoring and Evaluation System of the Millennium Villages Project-Potou/Senegal: Close Look at the Mid-term Evaluation Report. Consilience: The Journal of Sustainable Development Vol. 9, Iss. 1 (2012), Pp. 33 - 46

[7]. The Millennium Villages Project: The next five years: 2011-2015. www.millenniumvillages.org/reports/the-millenium-villages-project-the-next-five-years-2011-2015.

[8]. The Millennium Villages Project: An Overview, The Earth Institute, Millennium Promise \& UNDP, February 2007, p1.

[9]. The MDG Centre West and Central Africa, Earth institute/Columbia University http://www.mdgwca.org/en/clutter.php?mv=Ikaram\%20(Nigeria)\&PHPSESSID=fb2d40065601c63e9dd80eeaf8 61572

[10]. The Millennium Villages Project: Progress Report November 2006. www.undp.org.sn/new/mv/Newsletter [11]. UNDP, (2009). Handbook on planning, monitoring and evaluating for development results.

[12]. Xu K, Evans DB, Carrin G, Aguilar-Rivera AM, Musgrove P, Evans T. Protecting households from Catastrophic health expenditures. Health Affairs. 2007; 6:972-83. 